\title{
RENATE BLUMENFELD-KOSINSKI, The Strange Case of Ermine de Reims. A Medieval Woman Between Demons and Saints
}

G. Matteo Roccati

\section{OpenEdition}

\section{Journals}

Édition électronique

URL : https://journals.openedition.org/studifrancesi/12416

DOI : 10.4000/studifrancesi. 12416

ISSN : 2421-5856

Éditeur

Rosenberg \& Sellier

\section{Édition imprimée}

Date de publication : 1 avril 2018

Pagination : 109

ISSN : 0039-2944

\section{Référence électronique}

G. Matteo Roccati, « RENATE BLUmenfeld-Kosinski, The Strange Case of Ermine de Reims. A Medieval Woman Between Demons and Saints », Studi Francesi [En ligne], 184 (LXII | I) | 2018, mis en ligne le 04 juillet 2018, consulté le 15 novembre 2021. URL : http://journals.openedition.org/studifrancesi/12416 ; DOI : https://doi.org/10.4000/studifrancesi. 12416

Ce document a été généré automatiquement le 15 novembre 2021.

\section{(c) $(1)$}

Studi Francesi è distribuita con Licenza Creative Commons Attribuzione - Non commerciale - Non opere derivate 4.0 Internazionale. 


\title{
RENATE BLUMENFELD-KOSINSKI, The Strange Case of Ermine de Reims. A Medieval Woman Between Demons and Saints
}

\author{
G. Matteo Roccati
}

\section{RÉFÉRENCE}

RENATE BLUMENFELD-KOSINSKI, The Strange Case of Ermine de Reims. A Medieval Woman Between Demons and Saints, Philadelphia, University of Pennsylvania Press, 2015, « The Middle Ages Series», 236 pp.

1 A la fin du XIV ${ }^{\mathrm{e}}$ siècle, pendant les dix derniers mois de sa vie, très éprouvants, Ermine de Reims, paysanne pauvre et illettrée, a eu des visions que son confesseur Jean le Graveur a mises par écrit dans une sorte de journal. Les attaques quotidiennes des démons et les quelques moments de reconfort qu'elle a eus sont relatés dans un récit où on trouve également des références à l'actualité, notamment à la figure controversée de Jean de Varennes. L'A. présente avec beaucoup d'empathie ce "strange case" sur lequel Jean Gerson fut consulté, ce qui assura la notorieté de ces aventures. Le livre éclaire d'abord le contexte où se sont deroulés les faits : la ville de Reims à une époque troublée, l'état de veuve d'Ermine et la difficile situation économique où elle s'est trouvée, le cadre religieux et les modèles de sainteté féminine (chapitre 1). Il examine ensuite le "holy couple", qu'on retrouve dans plusieurs autres cas, du confesseur et de la sainte (ch. 2). La dévotion d'Ermine et sa dimension eucharistique, son éducation religieuse et ses pratiques ascétiques font l'objet du chapitre suivant (3), les deux derniers examinent les apparitions diaboliques : les démons ayant figure humaine ou animale (ch. 4) et ceux qui se présentent sous l'apparence de saints, où se pose donc la question du discernement des esprits (ch. 5). L'épilogue traite brièvement de la 
réception de l'œuvre, notamment à travers le témoignage des manuscrits. En appendice (pp. 157-186) sont donnés des longs extraits du texte en traduction anglaise. Bibliographie et index aux pp. 215-227 et 229-233. 